Check for updates

Cite this: RSC Adv., 2017, 7, 43083

\title{
Electrocatalytic water oxidation at amorphous trimetallic oxides based on $\mathrm{FeCoNiO}_{x}^{\dagger}$
}

\author{
Md Abu Sayeed and Anthony P. O'Mullane (D)*
}

Recently there has been a noticeable shift towards developing amorphous bimetallic or trimetallic oxides for electrochemical water splitting. However, the fabrication of a homogeneous mixed metal oxide electrocatalyst suitable for water electrolysis is not a facile process. Here we introduce an electrochemical synthesis method that is rapid, simple and performed under ambient conditions. Using this approach it is possible to create a catalytically active $\mathrm{FeCoNiO}_{x} \mathrm{H}_{y}$ amorphous material whose activity is dependent on the nature of the underlying support. The trimetallic oxide is significantly more active than any single or bimetallic oxide combination for the OER. This amorphous catalyst demonstrates not only excellent activity but also stability over extended time periods.

Received 20th July 2017

Accepted 27th August 2017

DOI: 10.1039/c7ra07995h

rsc.li/rsc-advances

electrodes for the OER. ${ }^{24}$ When the energetics of the water

\section{Introduction}

The ability to store energy from intermittent renewable energy sources is a significant challenge that can be addressed by generating hydrogen as a fuel via electrochemical water splitting. ${ }^{1-5}$ However, the sluggish kinetics of the oxygen evolution reaction (OER) is hampering this effort. The most commonly used electrocatalysts are $\mathrm{IrO}_{2}$ and $\mathrm{RuO}_{2}$ but these are prohibitively expensive due to their scarcity. Therefore, substantial commercial penetration of electrolysers has been hampered by a failure to fabricate inexpensive electrocatalysts that exhibit high current density at a low energy cost over prolonged periods. Consequently, addressing this major technological challenge has gained momentum and there has been significant progress in developing non-precious metal based earth abundant catalysts for better OER performance. ${ }^{1,6-9}$ In particular (oxy)-hydroxides or oxides of iron, nickel and cobalt have been studied due to their relatively higher abundance, lower cost and good performance in alkaline electrolytes for the OER. ${ }^{2,5,10-17}$ Recent work by Cao et al. have demonstrated that iron based thin films are highly active for the OER in neutral conditions, ${ }^{18,19}$ as well as hierarchical $\mathrm{Co}(\mathrm{OH}) \mathrm{F}$ superstructures $^{20}$ and porphyrin and corrole based systems. ${ }^{21}$ It is now generally regarded that bimetallic or trimetallic oxides perform better than monometallic $\mathrm{MO}_{x}$ systems. ${ }^{11-13,22,23}$ It has been shown that even iron impurities in the electrolyte can significantly enhance the performance of $\mathrm{CoO}_{x}$ and $\mathrm{NiO}_{x}$

School of Chemistry, Physics and Mechanical Engineering, Queensland University of Technology (QUT), GPO Box 2434, Brisbane, QLD 4001, Australia. E-mail: anthony. omullane@qut.edu.au

$\dagger$ Electronic supplementary information (ESI) available: XPS data for as-deposited films and films after OER, XRD data, chronoamperometry data recorded at Au and GC electrodes and SEM images showing the effect of deposition time and potential. See DOI: 10.1039/c7ra07995h oxidation process is considered for monometallic $\mathrm{MO}_{x}$ catalysts, the key intermediates such as $\mathrm{OH}, \mathrm{O}$ and $\mathrm{OOH}$ are adsorbed either too weakly or strongly on the surface which introduces a large overpotential ${ }^{15}$ and limits activity. Therefore having three components in the catalyst appears to solve this issue and promotes electrocatalytic activity through a synergistic effect.

Interestingly, there has been a shift from utilising crystalline catalysts to producing amorphous materials for water splitting. ${ }^{22,25-27}$ A recent study has shown that a photochemical metal-organic deposition process can produce amorphous mixed metal oxides displaying activity for the OER. ${ }^{22}$ Crystallinity or lack thereof is therefore expected to be a critical factor in determining the activity of the catalyst as evidence is now emerging that a reversible crystalline to amorphous transition can occur during the OER, as reported for $\mathrm{Co}_{3} \mathrm{O}_{4} \cdot{ }^{28}$ The formation of a thin amorphous layer at the surface of the crystalline metal oxide was found to be the active state for the OER, which reverted to the crystalline state once returned to non-catalytic conditions. Therefore, the formation of an amorphous homogeneous mixed metal oxide system that is active and robust is of significant interest for the OER.

Here we introduce an electrochemical protocol that results in the formation of a $\mathrm{FeCoNiO}_{x} \mathrm{H}_{y}$ material under ambient conditions that is evenly distributed over the substrate electrode and is highly active and durable for the OER. An electrochemical approach was taken due to simplicity, cost-effectiveness and good adherence to the underlying electrode compared to other deposition techniques that may be more involved for OER electrode preparation such as hydrothermal, co-sputtering and thermal decomposition techniques. 


\section{Results and discussion}

Cyclic voltammograms (CVs) recorded at a gold electrode in an electrolyte containing either $8 \mathrm{mM}$ of the hydrated salts of $\mathrm{Co}\left(\mathrm{NO}_{3}\right)_{2}, \mathrm{Ni}\left(\mathrm{NO}_{3}\right)_{2}$ or $\mathrm{Fe}\left(\mathrm{NO}_{3}\right)_{2}$ or an equimolar solution of all three salts is shown in Fig. 1. When taking a solution of $8 \mathrm{mM}$ $\mathrm{Co}\left(\mathrm{NO}_{3}\right)_{2}$ in water the cathodic current seen from -0.80 to $-1.20 \mathrm{~V}$ is due to the reduction of water via $2 \mathrm{H}_{2} \mathrm{O}+2 \mathrm{e}^{-} \rightarrow$ $2 \mathrm{OH}_{(\mathrm{aq})}{ }^{-}+\mathrm{H}_{2(\mathrm{~g})}$. The liberated $\mathrm{OH}^{-}$ions at the electrode surface complex with $\mathrm{Co}^{2+}$ ions to form $\mathrm{Co}(\mathrm{OH})_{2(\mathrm{~s})}$. An analogous process occurs for the case of $\mathrm{Ni}\left(\mathrm{NO}_{3}\right)_{2}$ as evidenced by a very similar voltammetric profile. In the case of $\mathrm{Fe}\left(\mathrm{NO}_{3}\right)_{3}$ slightly different behaviour is observed in that there is a peak at $0.05 \mathrm{~V}$ prior to the onset of the large cathodic current as seen for the other two metal salts, which is due to the reduction of $\mathrm{Fe}^{3+}$ to $\mathrm{Fe}^{2+}$. However iron hydroxide/oxide is formed in an analogous manner as reported elsewhere. ${ }^{29}$

For the equimolar solution containing all three metal salts the voltammogram is close to the addition of the three individual processes as evidenced by the large magnitude of current from -0.80 to $-1.20 \mathrm{~V}$. This result was further verified by the mathematical summation of the response from the individual reduction processes (Fig. $\mathrm{S} 1 \dagger$ ). It should be noted that there is a slight shift to more positive potentials $(c a .0 .15 \mathrm{~V})$ for all processes compared to the individual responses which may be due to the increased conductivity of the solution when three salts are present. Also in the CV it can be seen that there is current crossover between the forward and reverse scans which is highly indicative of nucleation growth phenomenon. ${ }^{30}$ This was analysed by performing current time transients (Fig. S2 $\dagger$ ) over a range of -0.70 to $-1.00 \mathrm{~V}$ and analysing the data by the Hills-Scharifker method ${ }^{31}$ where it was found that at early times (<3 s) instantaneous nucleation and growth occurs.

Initially it was confirmed that the electrodeposition of all three components did in fact enhance the OER compared to either individually deposited materials or the bimetallic combinations. A potential of $-0.95 \mathrm{~V}$ was chosen which is well within the water reduction process (Fig. 1) for a period of $90 \mathrm{~s}$. It can be seen from Fig. 2 that the trimetallic system gave the highest current density at an overpotential of $0.34 \mathrm{~V}$ when

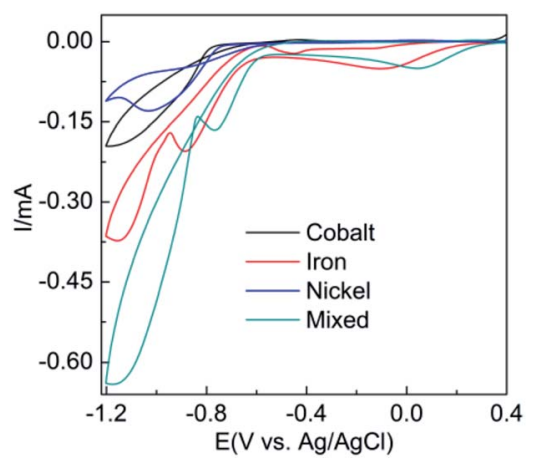

Fig. 1 Cyclic voltammograms obtained at $50 \mathrm{mV} \mathrm{s}^{-1}$ at an $\mathrm{Au}$ electrode in individual aqueous solutions containing $8 \mathrm{mM}$ of $\mathrm{Co}\left(\mathrm{NO}_{3}\right)_{2} \cdot 6 \mathrm{H}_{2} \mathrm{O}, \mathrm{Ni}\left(\mathrm{NO}_{3}\right)_{2} \cdot 6 \mathrm{H}_{2} \mathrm{O}, \mathrm{Fe}\left(\mathrm{NO}_{3}\right)_{2} \cdot 9 \mathrm{H}_{2} \mathrm{O}$ solution and an equimolar solution $(8 \mathrm{mM})$ of all three salts.

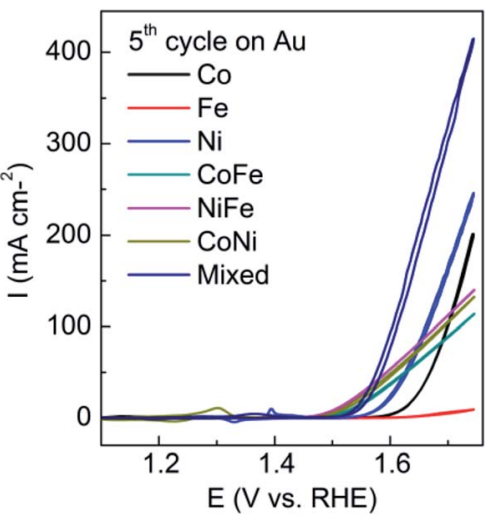

Fig. 2 Cyclic voltammograms recorded at $10 \mathrm{mV} \mathrm{s}^{-1}$ in $0.1 \mathrm{M} \mathrm{NaOH}$ for mono-, bi- and trimetallic oxides showing the 5 th cycle of the OER.

compared to mono or bimetallic systems (the 5th cycle is presented which ensured a stable response). In addition this material showed the lowest Tafel slope of $32 \mathrm{mV} \mathrm{dec}^{-1}$ when compared to all other combinations (Table S1 $\dagger$ ). Interestingly the FeCo and FeNi combinations reduced the overpotential but could not facilitate as high current densities. This data is consistent with previous work where the presence of iron, although very inactive itself in the potential range of interest, promotes the activity of Co and Ni oxides. ${ }^{13,32,33}$

It can be seen prior to the onset of oxygen evolution that there are significant faradaic processes occurring at the asdeposited materials which are illustrated in Fig. 3. For the individual $\mathrm{M}(\mathrm{OH})_{2}$ deposits characteristic redox processes can be seen for the $\mathrm{Co}(\mathrm{II}) / \mathrm{Co}(\mathrm{III})$ and $\mathrm{Ni}(\mathrm{II}) / \mathrm{Ni}(\mathrm{III})$ transitions with the latter process occurring at more positive potentials. For the case of iron hydroxide/oxide there are no oxidation processes in the potential range studied which is consistent with previous reports. ${ }^{32}$ For the CoNi hydroxide/oxide system it can be seen that the $\mathrm{CV}$ shows behaviour in a potential region between that of the individual components which indicates good electronic communication between the materials. For FeCo and FeNi hydroxide/oxide the inclusion of iron has a significant impact

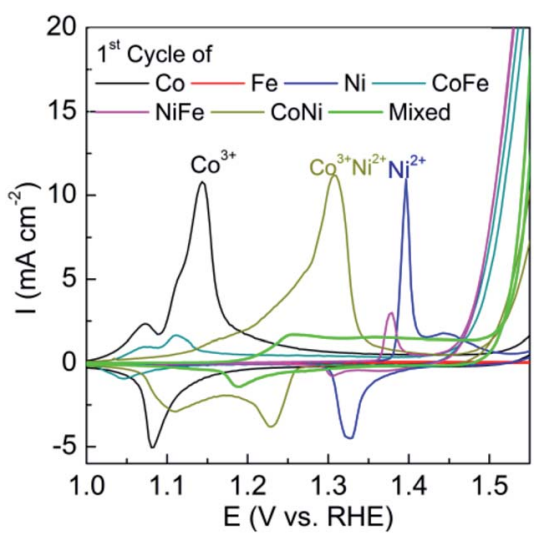

Fig. 3 Cyclic voltammograms recorded at $10 \mathrm{mV} \mathrm{s}^{-1}$ in $0.1 \mathrm{M} \mathrm{NaOH}$ for mono-, bi- and trimetallic oxides showing the 1st cycle prior to the OER. 
on the voltammetry which is evidenced by a dramatic reduction in the peak intensities and shift to less positive potentials for both the $\mathrm{Co}$ (II)/Co(III) and $\mathrm{Ni}$ (II)/Ni(III) transitions. The inclusion of iron also results in a dramatic increase in the OER current towards the end of the sweep which is much greater than that seen for the CoNi case. This is consistent with the recent work by Strasser who demonstrated that the incorporation of Fe into nickel oxide can increase the OER rate by 1-2 orders of magnitude. ${ }^{13}$ Finally for the trimetallic FeCoNi sample there is a broad oxidation process from 1.2 to $1.5 \mathrm{~V}$ prior to the onset of the OER. Although the onset for the OER is slightly more positive compared to the bimetallic samples containing iron the current density that can be achieved with the trimetallic sample at slightly higher potentials is significantly greater (Fig. 1). Therefore given the enhanced performance in terms of current density that can be achieved the trimetallic system was investigated in detail. The optimum OER activity was then determined via applying different potentials and deposition times as shown in Fig. S3† and found to be $-0.95 \mathrm{~V}$ for $90 \mathrm{~s}$. These conditions also resulted in the best long term performance of the electrocatalyst. A SEM image of the optimised sample is shown in Fig. 4. The formation of a layered sheet-like morphology with minimal cracks was observed which is indicative of $\mathrm{M}(\mathrm{OH})_{2}$ materials such as $\mathrm{Ni}(\mathrm{OH})_{2}$ and $\mathrm{Co}(\mathrm{OH})_{2}$ (ref. 34 and 35) and also consistent with iron oxyhydroxide films. ${ }^{36} \mathrm{SEM}-$ EDX analysis revealed a composition of $\mathrm{Fe}_{25} \mathrm{Co}_{40} \mathrm{Ni}_{35} \mathrm{O}_{x}$ (Fig. S4†) for the as-deposited material which is comparable with the X-ray photoelectron spectroscopy (XPS) data as $\mathrm{Fe}_{20} \mathrm{Co}_{37} \mathrm{Ni}_{43} \mathrm{O}_{x} \mathrm{H}_{y}$. This indicates that the final composition is different to the ratio of metal salts used during the electrodeposition process which were equimolar. Therefore this indicates that the electrodeposition of nickel and cobalt hydroxide is preferred over iron hydroxide.

However this material is unlikely to be the active species involved in the OER as reported previously for electrodeposited $\mathrm{Co}(\mathrm{OH})_{2} \cdot{ }^{35}$ Once $\mathrm{Co}(\mathrm{OH})_{2}$ is oxidised the composition changes to $\mathrm{Co}_{3} \mathrm{O}_{4}$ prior to the OER and then formation of $\mathrm{Co}$ (Iv) occurs which is responsible for oxygen evolution. ${ }^{37}$ Therefore the

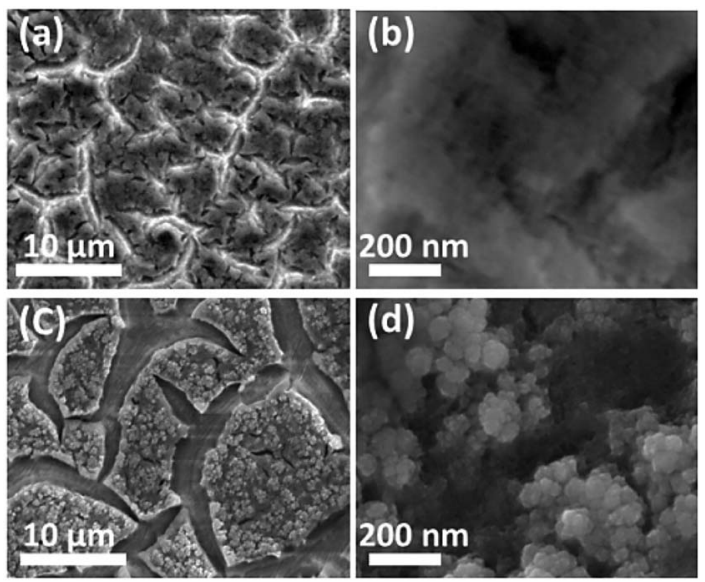

Fig. 4 SEM images of $\mathrm{FeCONiO}_{x} \mathrm{H}_{y}$ electrodeposited onto an $\mathrm{Au}$ electrode (a), (b) before and (c), (d) after OER.

sample was also imaged (Fig. 4c and d) after several potential cycles into the OER region over the range shown in Fig. 2. An interesting effect occurred whereby the surface loses its layered type structure and is replaced with a fractured surface containing isolated islands comprised of nodule like nanomaterials. EDX mapping of the reconstructed surface shows a highly even distribution of $\mathrm{Fe}, \mathrm{Co}, \mathrm{Ni}$ and $\mathrm{O}$ throughout the material without any evidence of phase segregation (Fig. 5 and $\mathrm{S} 5 \dagger$ ).

This is generally difficult to achieve with more conventional approaches such as thermal decomposition and coprecipitation. ${ }^{22}$ There is also clear exposure of the supporting gold electrode (Fig. 5) which in principle should be beneficial for oxygen evolution given the significant impact it has on the activity of cobalt oxide catalysts. ${ }^{7,35,37,38}$ The thickness of the asdeposited sample is $75 \mu \mathrm{m}$ which decreased slightly after the OER to $67 \mu \mathrm{m}$ (Fig. S6†).

The composition also changed compared to the as-deposited material and was determined to be $\mathrm{Fe}_{30} \mathrm{Co}_{30} \mathrm{Ni}_{40} \mathrm{O}_{x} \mathrm{H}_{y}$ by SEMEDX (Fig. S5 $\dagger$ ) and $\mathrm{Fe}_{30} \mathrm{Co}_{35} \mathrm{Ni}_{35} \mathrm{O}_{x} \mathrm{H}_{y}$ by XPS (Fig. 6) indicating a slight enrichment of $\mathrm{Fe}$ and $\mathrm{Ni}$ compared to the asdeposited material. Taking the Co $2 \mathrm{p}$ core level spectrum the binding energy of Co $2 \mathrm{p}_{3 / 2}$ (Fig. 6b) before the OER conversion process is $780.1 \mathrm{eV}$ with a clear satellite peak at higher energy which indicates the presence of $\mathrm{Co}(\mathrm{OH})_{2} \cdot{ }^{35}$ After the OER reaction the satellite peak is diminished, which indicates the formation of $\mathrm{Co}_{3} \mathrm{O}_{4}$ at the surface. For $\mathrm{Ni}$, the $\mathrm{Ni} 2 \mathrm{p}_{3 / 2}$ peak at a binding energy of $855.1 \mathrm{eV}$ (Fig. 6c) is indicative of $\mathrm{Ni}^{2+}$ species and is consistent with the formation of $\mathrm{NiO}$ and $\mathrm{Ni}(\mathrm{OH})_{2} \cdot{ }^{39}$ For Fe the Fe $2 \mathrm{p}_{3 / 2}$ peak at a binding energy of $710.8 \mathrm{eV}$ (Fig. $6 \mathrm{~d}$ ) is indicative of $\mathrm{Fe}_{2} \mathrm{O}_{3}$ which is consistent before and after the OER reaction. It has been reported previously ${ }^{29}$ that electrochemically reduced iron nitrate initially forms $\mathrm{Fe}(\mathrm{OH})_{2}$ but then converts readily to $\mathrm{Fe}_{2} \mathrm{O}_{3}$ which is consistent here with the as deposited material. ${ }^{40}$ The $\mathrm{O}$ 1s spectrum (Fig. 6e) before the OER can be deconvoluted into two components indicating a mixture of hydroxide (higher binding energy) and oxide states (lower binding energy). However, after the OER only one broad component is observable indicating the majority of the sample comprises of metal hydroxides ${ }^{41}$ or oxygen defects. Also shown in Fig. 6f shows the Au $4 \mathrm{f}$ core level spectra showing binding
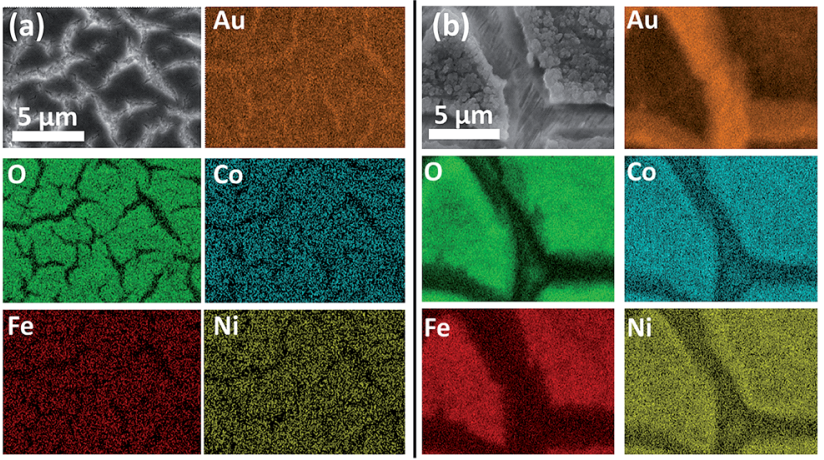

Fig. 5 SEM-EDX maps of $\mathrm{FeCONiO}_{x} \mathrm{H}_{y}$ electrodeposited onto an $\mathrm{Au}$ electrode (a) before and (b) after OER. 

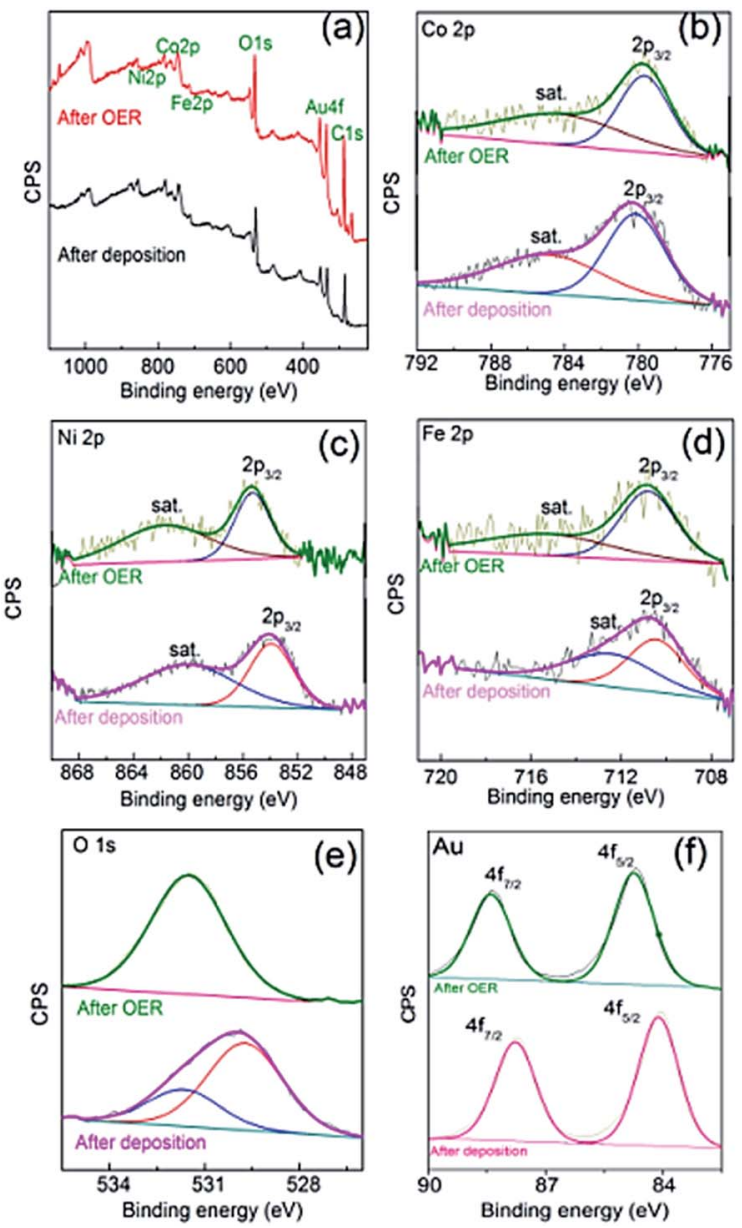

Fig. 6 XPS spectra showing (a) survey, (b) Co 2p, (c) Ni 2p, (d) Fe 2p, (e) $\mathrm{O}$ 1s and (f) $\mathrm{Au} 4 \mathrm{f}$, of $\mathrm{FeCoNiO}_{x}(\mathrm{Auu}$ as deposited (lower spectra) and after 5 cycles into the OER (upper spectra) in each case.

energies of $84.9 \mathrm{eV}$ and $88.5 \mathrm{eV}$ for $\mathrm{Au} 4 \mathrm{f}_{5 / 2}$ and $4 \mathrm{f}_{7 / 2}$, respectively which can be assigned to metallic $\mathrm{Au}^{0}$ of the underlying electrode..$^{42}$ The binding energy values shift by $2 \mathrm{eV}$ indicating the formation of an oxidised surface ${ }^{43}$ after the OER reaction. The composition of the catalyst before and after the OER was also analysed by laser ablation inductively coupled plasma mass spectrometry and found to change from $\mathrm{Fe}_{24} \mathrm{Co}_{44} \mathrm{Ni}_{32} \mathrm{O}_{x} \mathrm{H}_{y}$ to $\mathrm{Fe}_{28} \mathrm{Co}_{38} \mathrm{Ni}_{34} \mathrm{O}_{x} \mathrm{H}_{y}$ which is consistent with the EDX and XPS results.

To gain further insights into the structure of the materials, $\mathrm{FeCoNiO}_{x} \mathrm{H}_{y}$ was electrodeposited onto an Au coated (2-3 nm thick) TEM grid (Fig. 7a and b). EDS analysis with HRTEM shows that $\mathrm{FeCoNiO}_{x} \mathrm{H}_{y}$ was electrodeposited on the gold particles and the underlying carbon film (Fig. S7 $\dagger$ ). From the FFT images in the carbon only region (Fig. 7b), it was observed that the materials were mainly amorphous, however it must be noted that there are some spots in the FFT pattern which indicates some degree of crystallinity at the localised nanoscale level. Interestingly, after the OER the material showed evidence of a transition into a more crystalline state (Fig. 7d). However, XRD analysis of the bulk material before and after the OER was dominated by the underlying gold substrate (Fig. 8) and
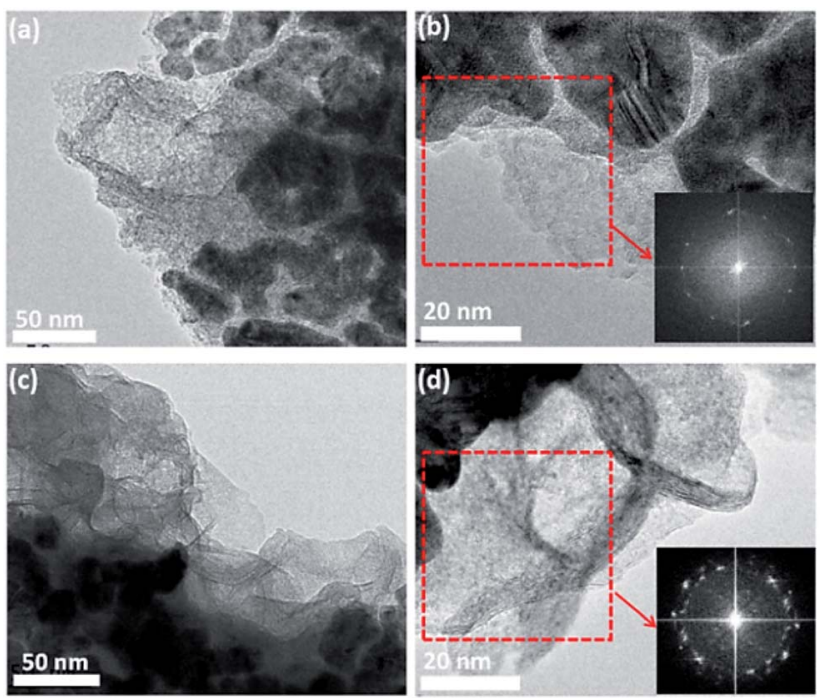

Fig. 7 HR-TEM images for ( $a, b)$ electrodeposited mixed hydroxide and $(c, d)$ post OER electrodeposited mixed hydroxide. The inset shows the FFT images.

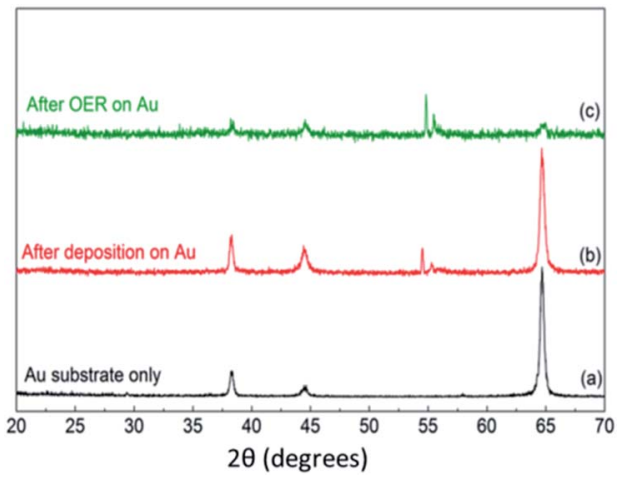

Fig. 8 GIXRD patterns of (a) Au substrate only, (b) $\mathrm{FeCoNiO}_{x} \mathrm{H}_{y} @ \mathrm{Au}$ after deposition and (c) $\mathrm{FeCONiO}_{x} \mathrm{H}_{y} @ \mathrm{Au}$ after 5 cycles of OER.

suggests that this amorphous to crystalline transition does not extend through the bulk of the electrodeposited material. It is interesting that the gold peaks are suppressed after the OER which may indicate that the gold is being oxidised quite significantly during the process (Au film for this sample is $100 \mathrm{~nm}$ thick) which is expected at this applied potential. ${ }^{44}$ The two peaks around $2 \theta=55^{\circ}$ which shift after the OER were unable to be assigned and did not correspond to any mono-, bior tri-metallic oxide/hydroxide. Given the absence of any other major peaks at lower values does suggest the material is amorphous.

It was also found that the underlying electrode influenced the OER whereby a gold electrode was found to show significantly better performance over glassy carbon (GC), Pd or $\mathrm{Cu}$ support electrodes (Fig. 9). Although the first cycle for $\mathrm{FeCoNiO}_{x} \mathrm{H}_{y}$ deposited on GC showed similar behaviour to that on $\mathrm{Au}$ the current density quickly diminished after 5 cycles (Fig. 9b) and demonstrated less activity than both $\mathrm{Pd}$ and $\mathrm{Cu}$ support electrodes. The Tafel slope for the OER at $\mathrm{FeCoNiO}_{x} \mathrm{H}_{y}$ 

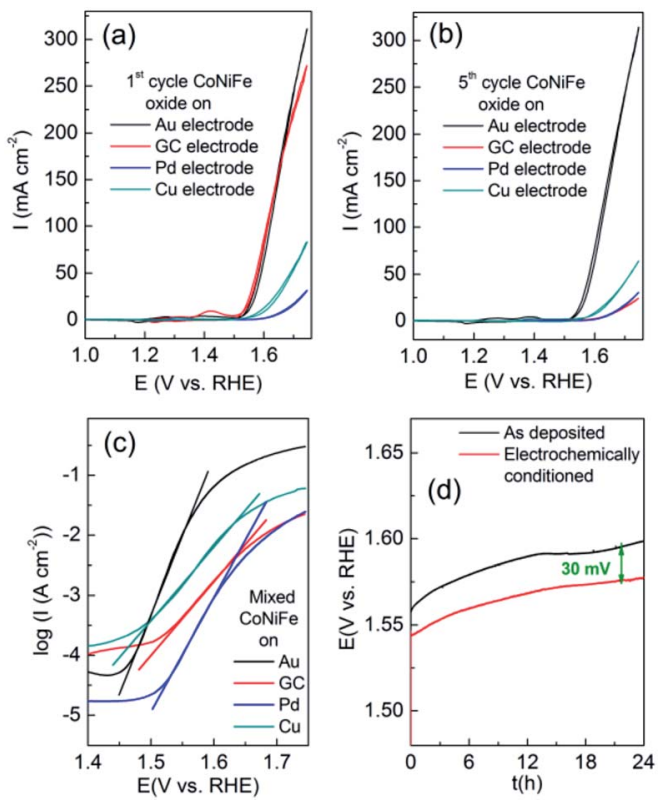

Fig. 9 Cyclic voltammograms recorded at $10 \mathrm{mV} \mathrm{s}^{-1}$ in $0.1 \mathrm{M} \mathrm{NaOH}$ of $\mathrm{FeCONiO}_{x} \mathrm{H}_{y}$ at (a) 1st cycle, (b) 5th cycle, (c) Tafel slope of $\mathrm{FeCONiO}_{x} \mathrm{H}_{y}$ on $\mathrm{Au}, \mathrm{GC}, \mathrm{Pd}, \mathrm{Cu}$ and (d) chronopotentiometric stability measurements of $\mathrm{FeCoNiO}_{x} \mathrm{H}_{y}$ on $\mathrm{Au}$ held at $10 \mathrm{~mA} \mathrm{~cm}{ }^{-2}$ for $24 \mathrm{~h}$ before restructuring and after restructuring.

on the different substrates (Au, GC, Pd and $\mathrm{Cu}$ ) after 5 cycles was determined to be $32,84,52$ and $73 \mathrm{mV} \mathrm{dec}^{-1}$ respectively, implying a significant dependence on the substrate for the OER (Fig. 9c). It should be noted that the morphology of $\mathrm{FeCoNiO}_{x} \mathrm{H}_{y}$ deposited on GC is distinctly different compared to $\mathrm{Au}$ (Fig. S8 $\dagger$ ). The surface is fractured and does not contain the layered type structure seen for the case of Au (Fig. 4). However from SEM-EDX analysis (Fig. S9†) the composition is comparable $\left(\mathrm{Fe}_{30} \mathrm{Co}_{34} \mathrm{Ni}_{36} \mathrm{O}_{x} \mathrm{H}_{y}\right)$ on a GC electrode. After the OER parts of the film were compromised but in general the morphology remained intact indicating that a significant restructuring process did not occur. Previous work on cobalt oxide catalysts postulated that underlying metals act as electron sinks to promote the formation of the $\mathrm{Co}(\mathrm{Iv})$ oxidation state which is regarded as the active site for oxygen evolution. ${ }^{7}$ This may also play a role here given the high percentage of cobalt in the trimetallic oxide sample.

Determining the main active site for the OER however is a challenging issue that is difficult to address. Recently however, Strasser ${ }^{13}$ has shown for the FeNi system that the buildup of higher oxidation states of $\mathrm{Ni}(\mathrm{Iv})$ and $\mathrm{Fe}(\mathrm{Iv})$ is followed by $\mathrm{O}-\mathrm{O}$ bond formation with the subsequent release of molecular oxygen. This process restores the metal site back to its reduced state. Once the $\mathrm{Fe}$ level is above $4 \%$ the rate of oxygen evolution is greater than the rate of metal oxidation and therefore lower valent metal centres are stabilised during catalysis and the active centre was determined to be $\mathrm{Ni}^{2+} \mathrm{Fe}^{3+} \mathrm{OOH}$. Recent spectroscopic characterization of mixed $\mathrm{Fe}-\mathrm{Ni}$ oxide electrocatalysts indicated that a $\mathrm{NiFe}_{2} \mathrm{O}_{4}$ phase was a contributing factor to enhanced OER activity as well as the presence of basic active sites..$^{45}$ Bell et al. ${ }^{46}$ have also reported that Ni-Fe catalysts are active for the OER whereby the incorporation of iron into the film increases the potential at which the $\mathrm{Ni}(\mathrm{OH})_{2} / \mathrm{NiOOH}$ redox process occurs and decreases the average oxidation state of $\mathrm{Ni}$ in $\mathrm{NiOOH}$ which results in an increase in activity for the OER.$^{46} \mathrm{CaO}$ et al. have also investigated the Fe-Ni system in detail ${ }^{47-49}$ and described additional effects that promote OER activity such as the embedded Fe(III) increases charge mobility due to more oxygen vacancies that facilitate polaron hopping between neighbouring atoms as well as the creation of surface defects for the coordination of reactive species. As seen from Fig. 2 and 3 the incorporation of Fe into cobalt also enhances activity at low overpotentials and therefore an analogous process may be taking place. However the nature of the underlying electrode was not investigated and may have an influence on the processes taking place. The combination of electronic interaction between the catalyst layer and the support, the critical presence of $\mathrm{Fe}$, and the surface morphology changes that occur, greatly influence OER activity.

The turnover frequency (TOF) is an excellent way to benchmark these materials as getting accurate surface areas for electrodeposited materials on this scale is not straightforward. As discussed by Lyons $e t$ al. the electrochemical equivalent of the TOF can be described by: ${ }^{50}$

$$
\mathrm{TOF}=1 N_{\mathrm{A}} / 4 F N_{\text {atoms }}=J / 4 Q
$$

where, $N_{\mathrm{A}}$ is Avagardo's number, $F$ is Faraday's constant, $N_{\text {atoms }}$ is the number of atoms or active sites, $J$ is the current density and $Q$ is the charge associated with the oxidation of $\mathrm{FeCoNiO}_{x} \mathrm{H}_{y}$. The TOF value obtained for the stabilised catalyst (5th cycle) at a current density of $10 \mathrm{~mA} \mathrm{~cm}^{-2}$ was determined to be $2.1 \mathrm{~s}^{-1}$, which is high compared to many other catalysts of this type (Table S1 $\dagger$ ). The stability of the catalyst was then tested under conditions of constant current $\left(10 \mathrm{~mA} \mathrm{~cm}^{-2}\right)$ Fig. $9 \mathrm{~d}$ over a period of $24 \mathrm{~h}$ for the as-deposited material and for the material subjected to $5 \mathrm{CVs}$ over the range of 1.0 to $1.75 \mathrm{~V}$ (as in Fig. 2). The five cycles of pre-conditioning of the catalyst is highly beneficial for long term performance as the potential attained by the system is lower over the entire $24 \mathrm{~h}$ period. In addition the conditioned catalyst only shows a $30 \mathrm{mV}$ increase in overpotential which is promising for commercial application. This method to produce a highly active yet stable catalyst is attractive in its simplicity and could in principle be adopted for deposition onto larger area supports.

\section{Experimental}

\section{Chemicals}

Cobalt(II) nitrate hexahydrate, iron(III) nitrate nonahydrate (Chem-Supply), nickel(II) nitrate hexahydrate (Alfa Aesar) and sodium hydroxide (98\%) (Sigma-Aldrich) were used as received and made up with deionised water (resistivity of $18.2 \mathrm{M} \Omega \mathrm{cm}$ ) purified by use of a Milli-Q reagent deioniser (Millipore). The plating solution for the mixed CoNiFe oxide nanostructures consisted of $8 \mathrm{mM}$ each of $\mathrm{Co}\left(\mathrm{NO}_{3}\right)_{2} \cdot 6 \mathrm{H}_{2} \mathrm{O}, \mathrm{Ni}\left(\mathrm{NO}_{3}\right)_{2} \cdot 6 \mathrm{H}_{2} \mathrm{O}$ and $\mathrm{Fe}\left(\mathrm{NO}_{3}\right)_{3} \cdot 9 \mathrm{H}_{2} \mathrm{O}$. 


\section{Electrochemical characterization}

Electrochemical measurements were undertaken at $(20 \pm 2){ }^{\circ} \mathrm{C}$ with a BioLogic VSP workstation equipped with a Rotating Ring Disk Electrode-3A (RRDE) assembly and a standard threeelectrode cell configuration, consisting of a working electrode, reference electrode $(\mathrm{Ag} / \mathrm{AgCl}(3 \mathrm{M} \mathrm{KCl}))$ and counter electrode (Pt wire). For OER experiments, Au (3 mm diameter), GC (3 mm diameter), $\mathrm{Pd}$ (3 $\mathrm{mm}$ diameter) or $\mathrm{Cu} \mathrm{RDE}$ (1.6 $\mathrm{mm}$ diameter) from BAS Inc. were used. The surface was mechanically polished with $0.3 \mu \mathrm{m}$-sized alumina powder on a Microcloth pad and rinsed in Milli-Q water. For all electrochemical experiments the electrolyte was initially purged for $10 \mathrm{~min}$ with nitrogen gas. For chronoamperometric experiments the potential was stepped from $0 \mathrm{~V}$ to the deposition potential of interest. For the OER the catalyst which was deposited on a RDE was rotated at $1500 \mathrm{rpm}$ in $0.1 \mathrm{M} \mathrm{NaOH}$. The reproducibility of the measurements was checked by carrying out four replicates for each OER experiment which is shown in Fig. S10. $\dagger$ The as electrodeposited mixed metal oxide/hydroxide was washed with deionised water for at least 3 times before the characterizations. In all cases $i R$ correction was applied to cyclic voltammograms and the potential for the OER data has been converted to the RHE scale via $E_{\mathrm{RHE}}=E_{\mathrm{Ag} / \mathrm{AgCl}}+0.059 \times \mathrm{pH}+0.197 \mathrm{~V}$. The current density reported in this work is normalized to the geometric surface area of the electrodes and was also used in the TOF calculation. The cyclic voltammetric experiments used to obtain the Tafel data were recorded at a sweep rate of $1 \mathrm{mV} \mathrm{s}^{-1}$.

\section{Structural characterization}

SEM and EDX were performed on JEOL 7001F at an operating voltage of $5 \mathrm{kV}$ and $15 \mathrm{kV}$, respectively. Samples were prepared by electrodeposition onto $100 \mathrm{~nm}$ thick $\mathrm{Au}$ coated silicon substrates following the same parameters used for the $\mathrm{Au}$ electrode (BAS), followed by rinsing with Milli-Q water to remove any metals salts and drying with a flow of nitrogen. The active area on the Au coated silicon substrates was carefully controlled using a mask ( $\sim 17 \mathrm{~mm}$ diameter). X-ray photoelectron spectroscopy data were collected using an Omicron Multiscan Lab Ultra-high Vacuum Scanning Tunnelling Microscope (UHV-STM) incorporating a $125 \mathrm{~mm}$ hemispherical electron energy analyser. XPS measurements were performed using nonmonochromatic $\mathrm{Mg} \mathrm{K} \alpha(1253.6 \mathrm{eV})$ X-ray source (DAR 400, Omicron Nanotechnology), $300 \mathrm{~W}$ incident angle at $65^{\circ}$ to the sample surface. Wide scans were observed at an analyser pass energy of $50 \mathrm{eV}$ with $0.5 \mathrm{eV}$ steps and $200 \mathrm{~ms}$ dwell time. Narrow high-resolution scans for Co 2p, O 1s, Au 4f, and C 1s were taken at $20 \mathrm{eV}$ pass energy, $0.2 \mathrm{eV}$ steps, $200 \mathrm{~ms}$ dwell time. The base pressure in the analysis chamber was $1.0 \times 10^{-9}$ Torr and $1.0 \times$ $10^{-8}$ Torr when the sample was analysed. HRTEM images were taken using a JEOL 2100 instrument at 200 KV. A highsensitivity silicon drift X-ray detector for more accurate compositional analysis and a Gatan Orius SC1000 CCD camera is equipped for better image acquisition. Ultrathin gold supported films on $3 \mathrm{~mm}$ standard TEM grids (Substratek ${ }^{\mathrm{TM}}$, TED PELLA) were used as the working electrode for the electrodeposition of $\mathrm{FeCoNiO}_{x} \mathrm{H}_{y}$. Laser ablation of samples took place in a He atmosphere $\left(0.85 \mathrm{l} \mathrm{min}^{-1}\right)$ in a ESI New Wave "TV" cell attached to a ATL excimer laser. The laser was fired at $6 \mathrm{~Hz}$ and the spot size was 85 microns. The laser output fluence was about $2 \mathrm{~J} \mathrm{~cm}^{-2}$ and the fluence at the sample was approximately $25 \%$ of that. Samples were either drilled or rastered. The reference material used in the experiment was NIST-610, a silicate glass. Samples were drilled until the silicon substrate was $100 \%$ of the signal. The ablated material in the carrier He gas was Y-ed into an argon gas flow at $11 \mathrm{~min}^{-1}$ which entered the plasma of the Agilent 8800 ICPMS. The instrument was run in single MS mode with RF power at 1350 and no torch shield.

\section{Conflicts of interest}

There are no conflicts to declare.

\section{Acknowledgements}

AOM gratefully acknowledges funding through a Future Fellowship from the Australian Research Council (FT110100760). The XPS and SEM data reported in this paper were obtained at the Central Analytical Research Facility operated by the Institute for Future Environments (QUT). Access to CARF is supported by generous funding from the Science and Engineering Faculty (QUT).

\section{Notes and references}

1 I. Roger, M. A. Shipman and M. D. Symes, Nature Reviews Chemistry, 2017, 1, 0003.

2 M. E. G. Lyons, R. L. Doyle, M. P. Browne, I. J. Godwin and A. A. S. Rovetta, Current Opinion in Electrochemistry, 2017, 1, 40-45.

3 X. Li, X. Hao, A. Abudula and G. Guan, J. Mater. Chem. A, 2016, 4, 11973-12000.

4 S. Anantharaj, S. R. Ede, K. Sakthikumar, K. Karthick, S. Mishra and S. Kundu, ACS Catal., 2016, 6, 8069-8097.

5 X. Zou and Y. Zhang, Chem. Soc. Rev., 2015, 44, 5148-5180. 6 J. A. Koza, Z. He, A. S. Miller and J. A. Switzer, Chem. Mater., 2012, 24, 3567-3573.

7 B. S. Yeo and A. T. Bell, J. Am. Chem. Soc., 2011, 133, 55875593.

8 Y. Zhao, S. Chen, B. Sun, D. Su, X. Huang, H. Liu, Y. Yan, K. Sun and G. Wang, Sci. Rep., 2015, 5, 7629.

9 M. S. Burke, L. J. Enman, A. S. Batchellor, S. Zou and S. W. Boettcher, Chem. Mater., 2015, 27, 7549-7558.

10 T. Maiyalagan, K. A. Jarvis, S. Therese, P. J. Ferreira and A. Manthiram, Nat. Commun., 2014, 5, 3949.

11 Q. Luo, M. Peng, X. Sun, Y. Luo and A. M. Asiri, Int. J. Hydrogen Energy, 2016, 41, 8785-8792.

12 M. Görlin, M. Gliech, J. F. de Araújo, S. Dresp, A. Bergmann and P. Strasser, Catal. Today, 2016, 262, 65-73.

13 M. Görlin, P. Chernev, J. Ferreira de Araújo, T. Reier, S. Dresp, B. Paul, R. Krähnert, H. Dau and P. Strasser, J. Am. Chem. Soc., 2016, 138, 5603-5614. 
14 D. R. Chowdhury, L. Spiccia, S. S. Amritphale, A. Paul and A. Singh, J. Mater. Chem. A, 2016, 4, 3655-3660.

15 S. A. Bonke, A. M. Bond, L. Spiccia and A. N. Simonov, J. Am. Chem. Soc., 2016, 138, 16095-16104.

16 J. Nai, H. Yin, T. You, L. Zheng, J. Zhang, P. Wang, Z. Jin, Y. Tian, J. Liu, Z. Tang and L. Guo, Adv. Energy Mater., 2015, 5, 1401880.

17 M. S. Burke, S. Zou, L. J. Enman, J. E. Kellon, C. A. Gabor, E. Pledger and S. W. Boettcher, J. Phys. Chem. Lett., 2015, 6, 3737-3742.

18 M. Chen, Y. Wu, Y. Han, X. Lin, J. Sun, W. Zhang and R. Cao, ACS Appl. Mater. Interfaces, 2015, 7, 21852-21859.

19 Y. Wu, M. Chen, Y. Han, H. Luo, X. Su, M.-T. Zhang, X. Lin, J. Sun, L. Wang, L. Deng, W. Zhang and R. Cao, Angew. Chem., Int. Ed., 2015, 54, 4870-4875.

20 S. Wan, J. Qi, W. Zhang, W. Wang, S. Zhang, K. Liu, H. Zheng, J. Sun, S. Wang and R. Cao, Adv. Mater., 2017, 29, 1700286.

21 W. Zhang, W. Lai and R. Cao, Chem. Rev., 2017, 117, 37173797.

22 R. D. L. Smith, M. S. Prévot, R. D. Fagan, Z. Zhang, P. A. Sedach, M. K. J. Siu, S. Trudel and C. P. Berlinguette, Science, 2013, 340, 60-63.

23 J. Nai, Y. Tian, X. Guan and L. Guo, J. Am. Chem. Soc., 2013, 135, 16082-16091.

24 L. Trotochaud, S. L. Young, J. K. Ranney and S. W. Boettcher, J. Am. Chem. Soc., 2014, 136, 6744-6753.

25 W.-Y. Xia, N. Li, Q.-Y. Li, K.-H. Ye and C.-W. Xu, Sci. Rep., 2016, 6, 23398.

26 Y. Hou, M. R. Lohe, J. Zhang, S. Liu, X. Zhuang and X. Feng, Energy Environ. Sci., 2016, 9, 478-483.

27 J. Fan, Z. Chen, H. Shi and G. Zhao, Chem. Commun., 2016, 52, 4290-4293.

28 A. Bergmann, E. Martinez-Moreno, D. Teschner, P. Chernev, M. Gliech, J. F. de Araujo, T. Reier, H. Dau and P. Strasser, Nat. Commun., 2015, 6, 8625.

29 T. Yousefi, R. Davarkhah, A. Nozad Golikand, M. Hossein Mashhadizadeh and A. Abhari, Prog. Nat. Sci.: Mater. Int., 2013, 23, 51-54.

30 A. R. Harris, A. K. Neufeld, A. P. O'Mullane, A. M. Bond and R. J. S. Morrison, J. Electrochem. Soc., 2005, 152, C577-C583.
31 B. Scharifker and G. Hills, Electrochim. Acta, 1983, 28, 879889.

32 M. S. Burke, M. G. Kast, L. Trotochaud, A. M. Smith and S. W. Boettcher, J. Am. Chem. Soc., 2015, 137, 3638-3648.

33 R. D. L. Smith, M. S. Prévot, R. D. Fagan, S. Trudel and C. P. Berlinguette, J. Am. Chem. Soc., 2013, 135, 11580-11586.

34 C.-C. Hu, J.-C. Chen and K.-H. Chang, J. Power Sources, 2013, 221, 128-133.

35 M. A. Sayeed, T. Herd and A. P. O'Mullane, J. Mater. Chem. A, 2016, 4, 991-999.

36 K. W. Chung, K. B. Kim, S.-H. Han and H. Lee, J. Electrochem. Soc., 2005, 152, C560-C565.

37 X. Lu, Y. H. Ng and C. Zhao, ChemSusChem, 2014, 7, 82-86. 38 Z. Zhuang, W. Sheng and Y. Yan, Adv. Mater., 2014, 26, 39503955.

39 F. J. Pérez-Alonso, C. Adán, S. Rojas, M. A. Peña and J. L. G. Fierro, Int. J. Hydrogen Energy, 2015, 40, 51-61.

40 C. S. Lim, C. K. Chua, Z. Sofer, K. Klimova, C. Boothroyd and M. Pumera, J. Mater. Chem. A, 2015, 3, 11920-11929.

41 J.-C. Dupin, D. Gonbeau, P. Vinatier and A. Levasseur, Phys. Chem. Chem. Phys., 2000, 2, 1319-1324.

42 A. P. O'Mullane and S. K. Bhargava, Electrochem. Commun., 2011, 13, 852-855.

43 Y. Xue, X. Li, H. Li and W. Zhang, Nat. Commun., 2014, 5, 4348.

44 L. D. Burke, A. J. Ahern and A. P. O'Mullane, Gold Bull., 2002, $35,3-10$.

45 J. Landon, E. Demeter, N. İnoğlu, C. Keturakis, I. E. Wachs, R. Vasić, A. I. Frenkel and J. R. Kitchin, ACS Catal., 2012, 2, 1793-1801.

46 M. W. Louie and A. T. Bell, J. Am. Chem. Soc., 2013, 135, 12329-12337.

47 W. Zhang, Y. Wu, J. Qi, M. Chen and R. Cao, Adv. Energy Mater., 2017, 7, 1602547.

48 W. Zhang, J. Qi, K. Liu and R. Cao, Adv. Energy Mater., 2016, 6, 1502489.

49 J. Qi, W. Zhang, R. Xiang, K. Liu, H.-Y. Wang, M. Chen, Y. Han and R. Cao, Adv. Sci., 2015, 2, 1500199.

50 I. J. Godwin and M. E. G. Lyons, Electrochem. Commun., 2013, 32, 39-42. 